\title{
Post-shearing data collection with enhanced network smart markers
}

T Beingessner Teck Resources Limited, Canada

R Yost Teck Resources Limited, Canada

S Steffen Elexon Mining, Australia

D Whiteman Elexon Mining, Australia

AM Thomas SRK Consulting (Canada) Inc., Canada

M Royle SRK Consulting (Canada) Inc., Canada

E Widzykcapehart University of Chile, Chile

\begin{abstract}
Enhanced network smart markers (ENSMs) were installed at Teck's Highland Valley Copper (THVC) mine in an actively moving slope where standard downhole instrumentation is often damaged within weeks of installation and rendered inoperable. The ENSMs were used to monitor downhole deformation in the active shear zone and provide movement and water pressure data after the standard inclinometer and vibrating wire piezometer (VWP) installations were sheared.
\end{abstract}

ENSMs provide a new approach to monitoring subsurface deformation. As with any new technology, ENSM performance needed to be evaluated and validated for the data to be deemed reliable. The trial conducted at THVC was set up such that the ENSMs were installed along with traditional technology (inclinometers and VWPS). This enabled a direct comparison between the ENSMs and inclinometer/VWPs for the trial at THVC.

ENSMs were installed as downhole arrays, attached to inclinometer pipe and standard piezometers in two boreholes located on the Valley pit southeast wall. As the Valley pit mining sequence progressed downslope of the boreholes, deformations and pore pressure readings were recorded. This paper presents comparative deformations taken over a period of several months recorded by the ENSM system, versus readings recorded using a traditional inclinometer system. Additionally, pore pressure readings recorded by the ENSM system are compared to data recorded by traditional grouted in-place vibrating wire piezometers.

Deformations and pore pressure measurements generally correlate well, and discrepancies between the systems are discussed. There were many learnings from the trial, but the main success was following significant amounts of shearing in the wall, the ENSM system continued to yield data below the shear zone after the traditional instruments had been severed. This allowed for deformation and pressure data to be monitored below the shear for a longer period than was possible using traditional downhole slope monitoring methods.

Keywords: slope monitoring, enhanced network smart markers, ENSM, subsurface deformation, pore pressure monitoring, inclinometer, vibrating wire piezometer, survivability, longevity

\section{$1 \quad$ Introduction}

To understand pit slope movement and calibrate slope stability models, knowledge of the subsurface deformation mechanism is needed. Comprehensive monitoring systems combine surface methods (such as prisms, radar, InSAR, etc.) with subsurface methods (such as time-domain reflectometry, inclinometer, shape array, etc.). This information is used to interpret the mechanism, magnitude and depth of slope deformation. Typical subsurface monitoring methods experience varying levels of success and may fail entirely when large deformation shears casing and cables. A solution to this is enhanced network smart markers (ENSMs) which 
do not use cables for transmitting data or power. Versions similar to ENSMs have been used for many years in mass mining for monitoring aspects such as cave propagation, subsidence, ore flow and ore/waste recovery.

The hypothesis for the trial at THVC mine was that ENSMs would continue to communicate wirelessly even after ground shearing and loss of standard instruments. To investigate this, ENSMs were installed attached to standard inclinometer pipe in an area of deformation in the Valley pit. All ENSMs were configured to measure their local 'tilt' (rotation in 3D space) and several of them were configured to measure piezometric pressure. Standard VWPs were also installed to enable pressure data comparison. Readings from the instruments were collected over several months.

\section{$2 \quad$ Enhanced networked smart markers}

ENSMs comprise multiple instruments encapsulated in rugged, waterproof and blast-proof cases that operate wirelessly and are battery-powered (Figure 1). Onboard accelerometers and magnetometers detect changes in the gravity acceleration vector as the sensor tilts with the ground, and radio devices transmit and receive data. Ground deformation is calculated using the tilt and azimuth data.

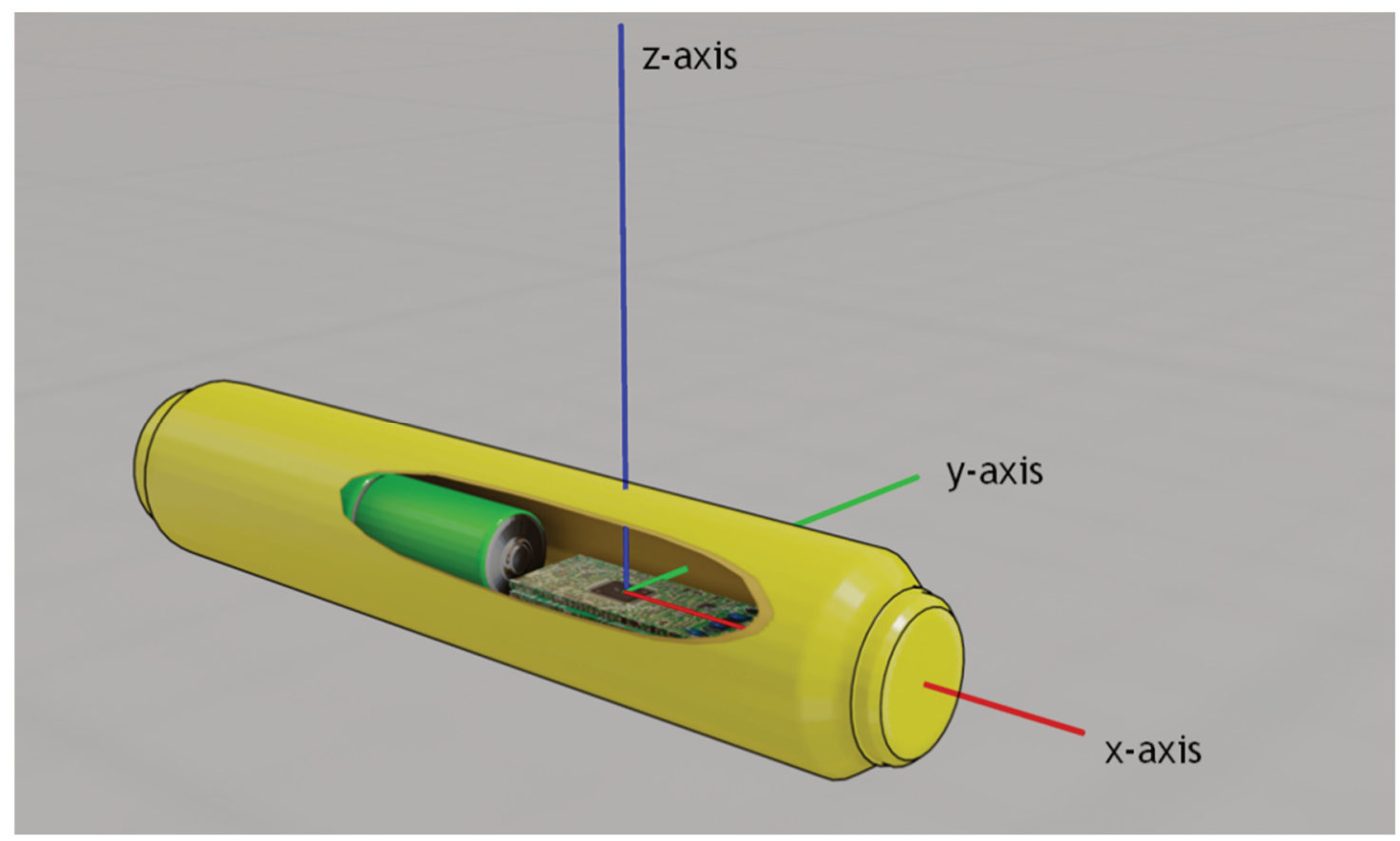

Figure 1 Enhanced network smart marker

Markers have a radio communication range of about $4.5 \mathrm{~m}$ through the ground, however, for redundancy and to allow for movement, they are typically installed much closer. Communication from the reader at the surface to any marker in the hole is done by sending 'queries' down the chain, passing from one to the next until the destination marker has been reached. When the query command is received, the destination marker takes measurements and sends the data back up the chain to the reader to be recorded and transmitted (Figure 2). 


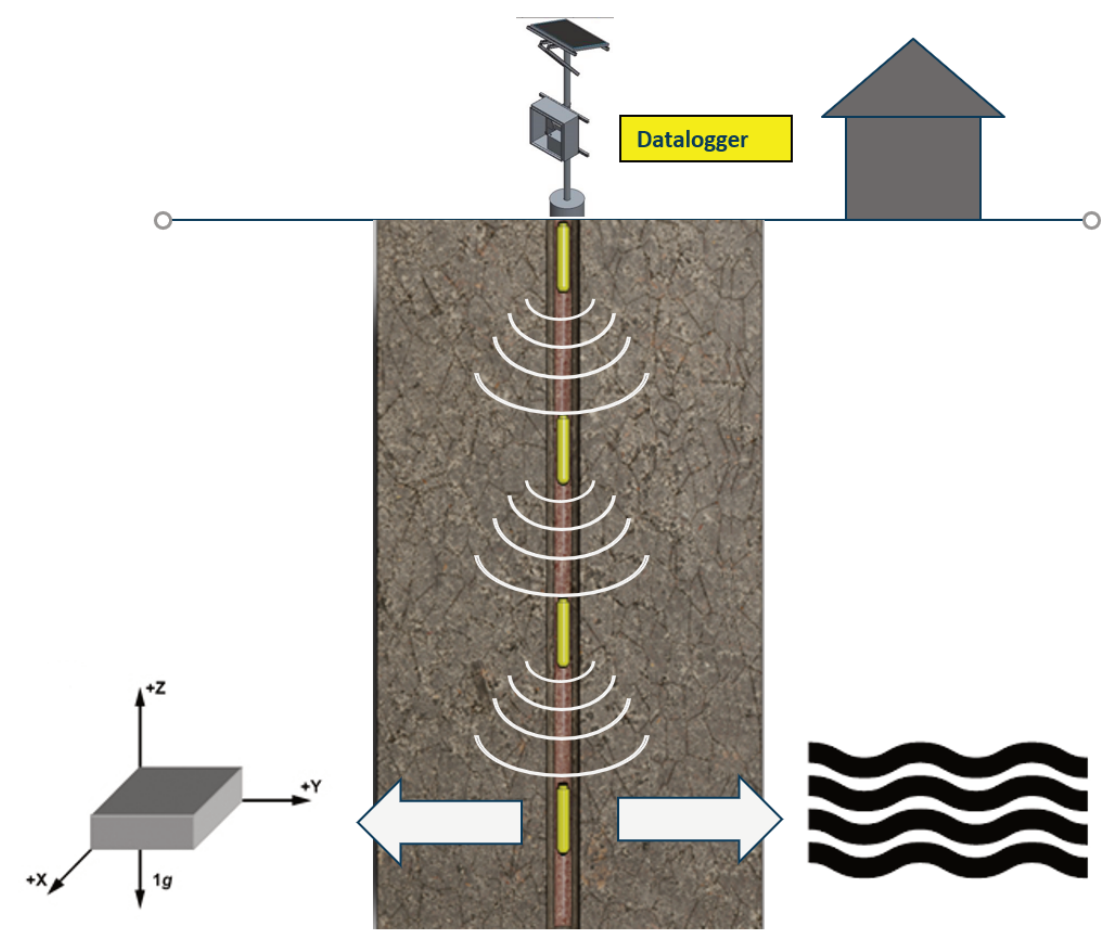

Figure 2 Enhanced network smart marker operating principles

Although not used for the trial, there are also ENSM models that contain sensors to measure radio signal strength and distance between markers. Marker-specific accelerometers and magnetometer tilt measurements can be passed from marker to marker when queried. Combining these measurements with tilt will give 3D movement of the markers from their initial installation positions. Radio signal strength measurements can be converted to distance with a sensitivity of about $50 \mathrm{~mm}$ (Figure 3).

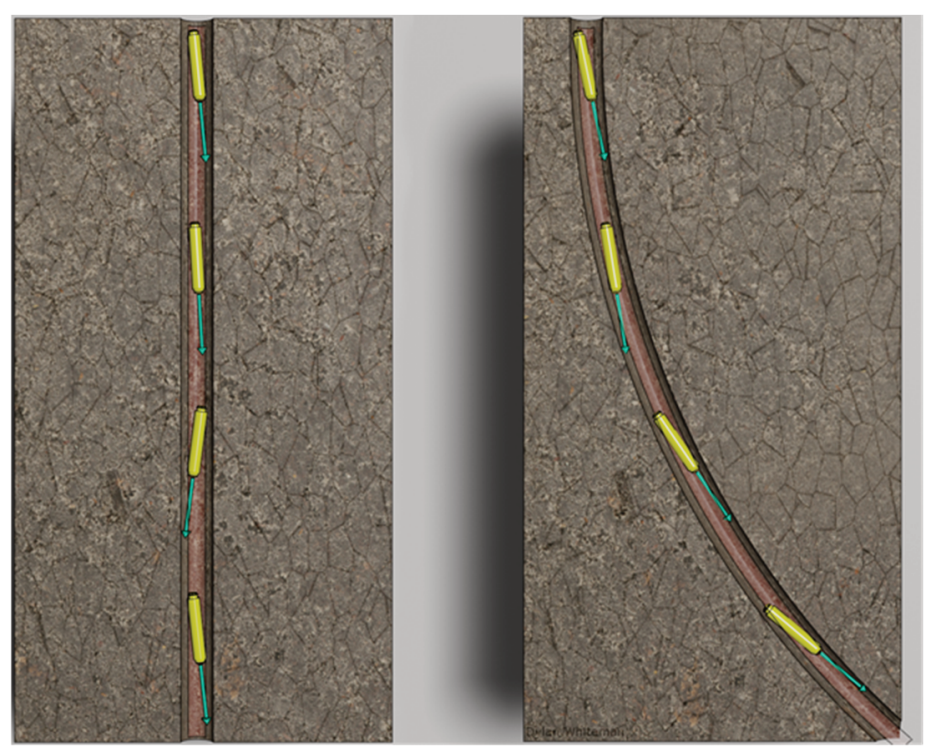

Figure $3 \quad$ Enhanced network smart markers deformation principle

\section{$3 \quad$ Trial details}

\subsection{Enhanced network smart markers, piezometer and inclinometer installation}

Inclinometer pipe and markers were installed in two 6 in diameter, $100 \mathrm{~m}$ long vertical drillholes at the locations shown in Figure 4. The casing was installed such that the A+ axis was perpendicular to the slope 
(311.5 and $288.4^{\circ}$ in DP306 and DP307, respectively). Markers were attached to the inclinometer pipe at approximately $2 \mathrm{~m}$ centres (Figure 5). The pipe was anchored and capped at the bottom to prevent floating and grout ingress. The annulus of the borehole was grouted according to the fully grouted method (Mikkelson \& Green 2003) with a cement/bentonite ratio of 3:1. RST Instruments VWP-2100 piezometers were also attached to the inclinometer casing. Depths of the VWPs and ENSMs equipped with pressure transducers are listed in Table 1.

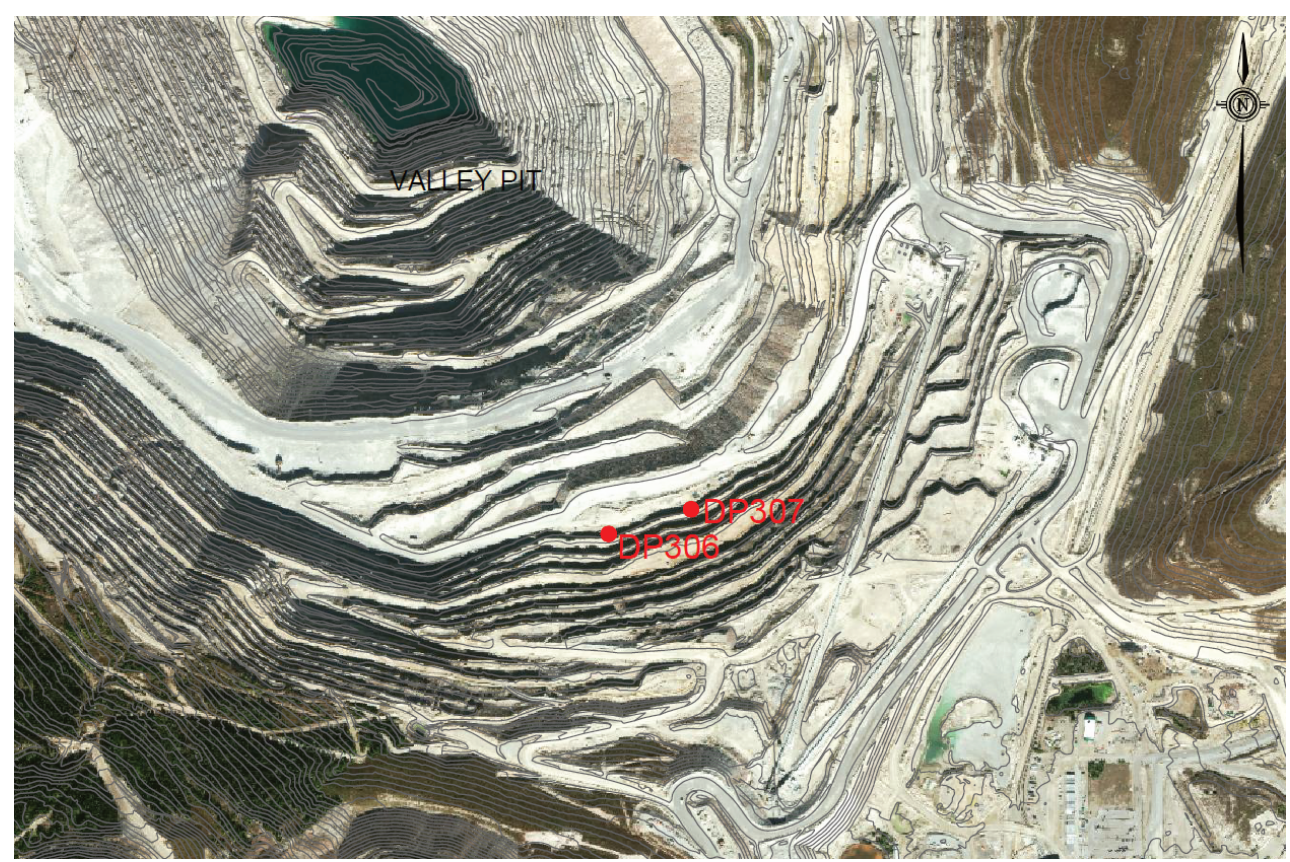

Figure 4 Plan view of enhanced network smart markers installations in Valley pit

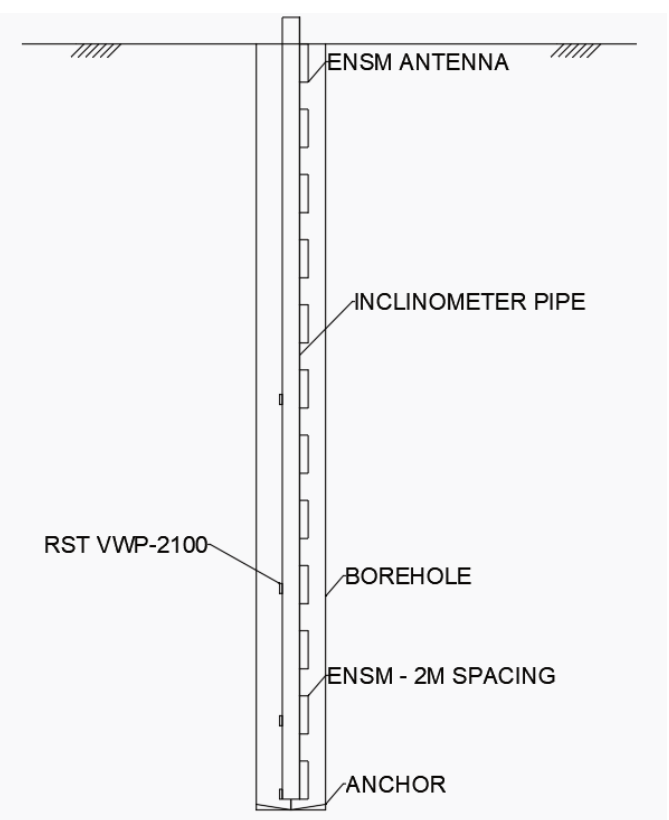

Figure 5 Enhanced network smart markers and vibrating wire piezometers installed on inclinometer casing (typical, not to scale) 


\begin{tabular}{|c|c|c|c|c|c|c|c|}
\hline \multicolumn{4}{|l|}{ DP306 } & \multicolumn{4}{|l|}{ DP307 } \\
\hline 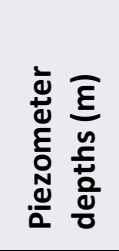 & 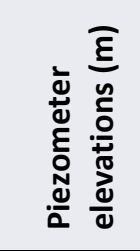 & 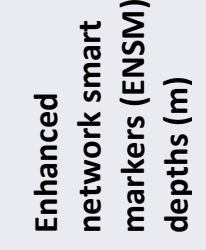 & 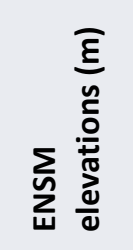 & 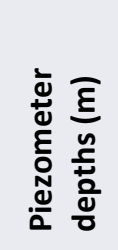 & 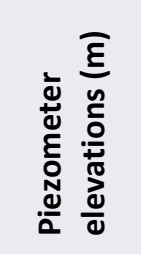 & 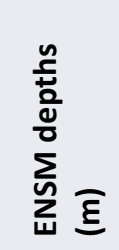 & 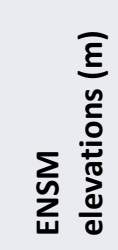 \\
\hline 19.5 & $1,112.2$ & 36.0 & $1,095.8$ & 39.6 & $1,090.4$ & 34.4 & 1,096 \\
\hline 39.5 & $1,092.2$ & 44.1 & $1,087.6$ & & & 46.7 & 1,083 \\
\hline 49.5 & $1,082.2$ & 66.7 & $1,065.0$ & & & 83.6 & 1,046 \\
\hline 69.5 & $1,062.2$ & 70.7 & $1,061.0$ & & & 89.7 & 1,040 \\
\hline 98.5 & $1,033.2$ & & & & & & \\
\hline
\end{tabular}

\subsection{Geotechnical units}

The instrumentation for the study was installed in the 'avalanche' and 'upper tertiary' units. The avalanche unit is interpreted to be fault gouge material that has been transported by landslide, is comprised of Lornex Fault Zone source material, and is deposited on top of the tertiary units. The upper tertiary unit is comprised of carboniferous, coal-bearing sedimentary deposit featuring slickensides throughout the coal horizons. The lateral continuity of the tertiary units is currently unknown. The primary shear zone within the slope is located along the contact of the avalanche and tertiary units, which is expected to deform over a wide area. THVC slope designs for the avalanche and tertiary units incorporate a series of large buttresses to mitigate slope deformations.

Geotechnical conditions and details on slope movement are presented in separate papers and reports (e.g. Rose 2015).

\section{Deformation data collected}

\subsection{Inclinometer deformation data}

Inclinometer data was collected using a standard RST inclinometer manual reader and processed using RST IncliAnalysis (RST Instruments Ltd 2012) software. As a result of the inclinometer pipe shearing, approximately three weeks after installation in DP306 and DP307, the data could no longer be processed with the same bottom of hole null value for the cumulative plots. As such, cumulative deformation plots are presented in Figures 6 to 9 for the 'top-down' processing method, which was done to maintain a consistent null value (as opposed to a more rigorous calculation method). The 'bottom-up' method was also reviewed as part of the data review but is not presented herein. The null values in the cumulative 'bottom-up' plots correspond to the lowest elevation value from each reading as the inclinometer pipe progressively sheared.

For reference, the A+ groove azimuths for holes DP306 and DP307 were $311.5^{\circ}$ and $288.4^{\circ}$, respectively. 


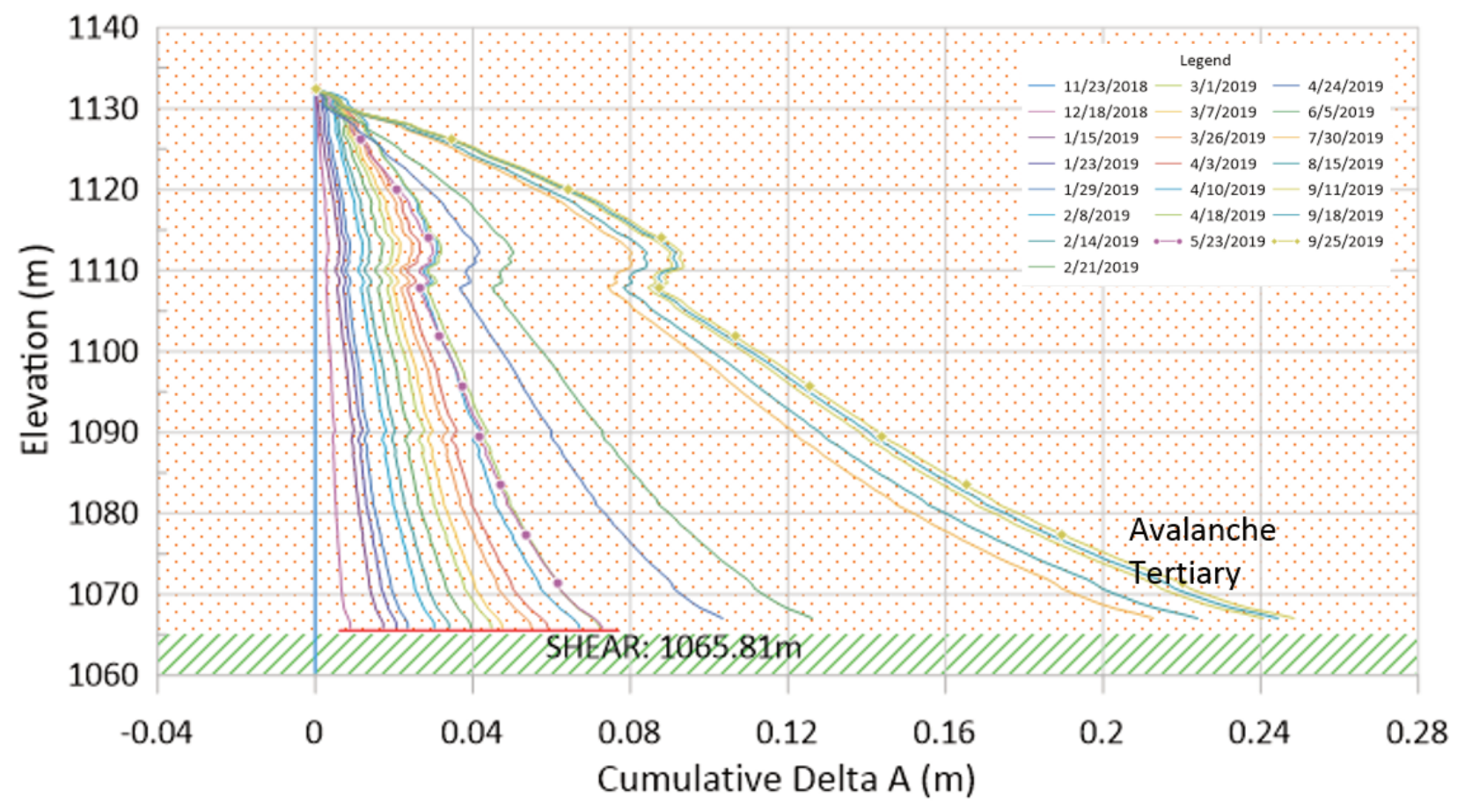

Figure 6 DP306 cumulative $A$ axis (top-down)

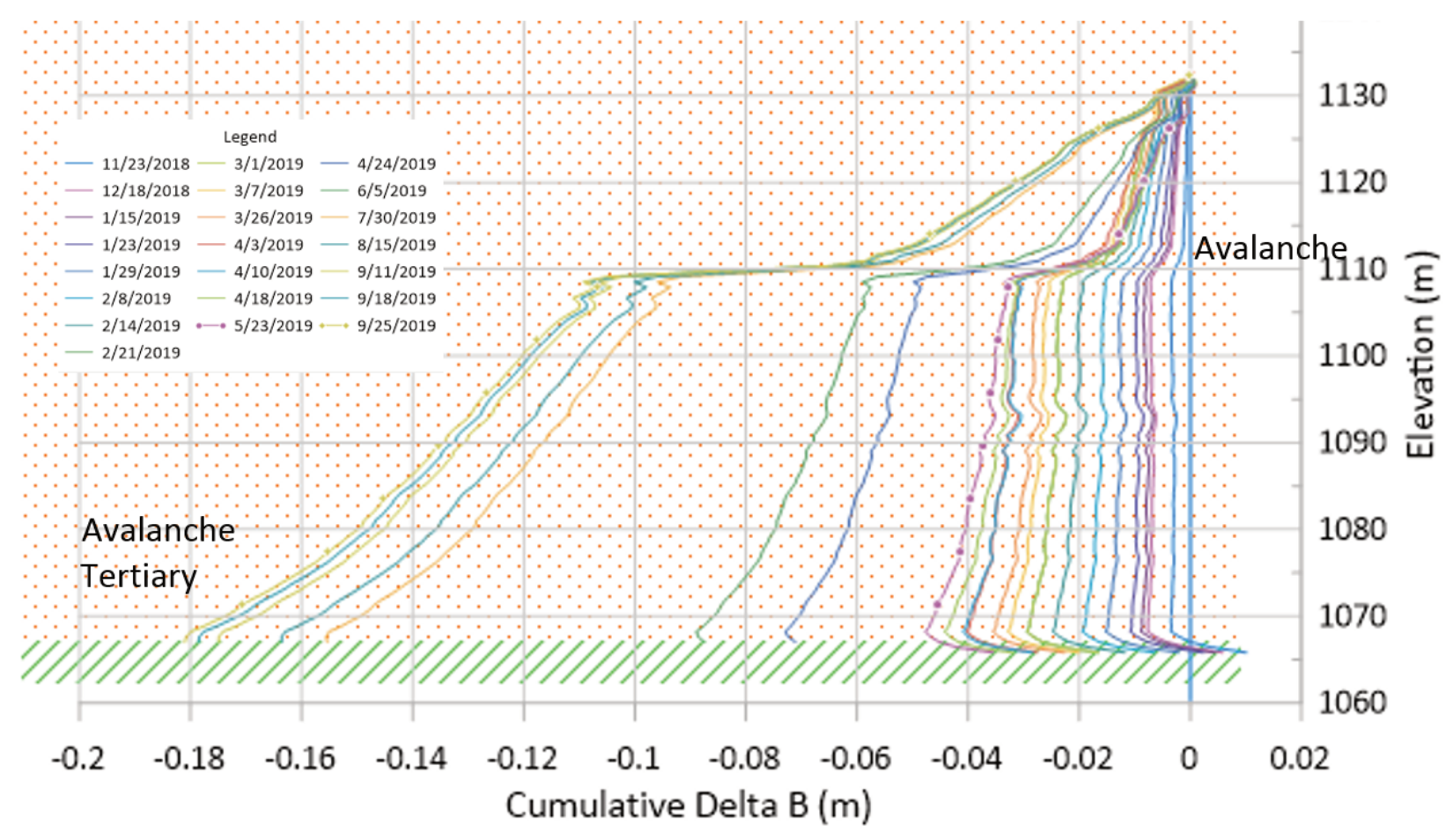

Figure 7 DP306 cumulative B axis (top-down) 


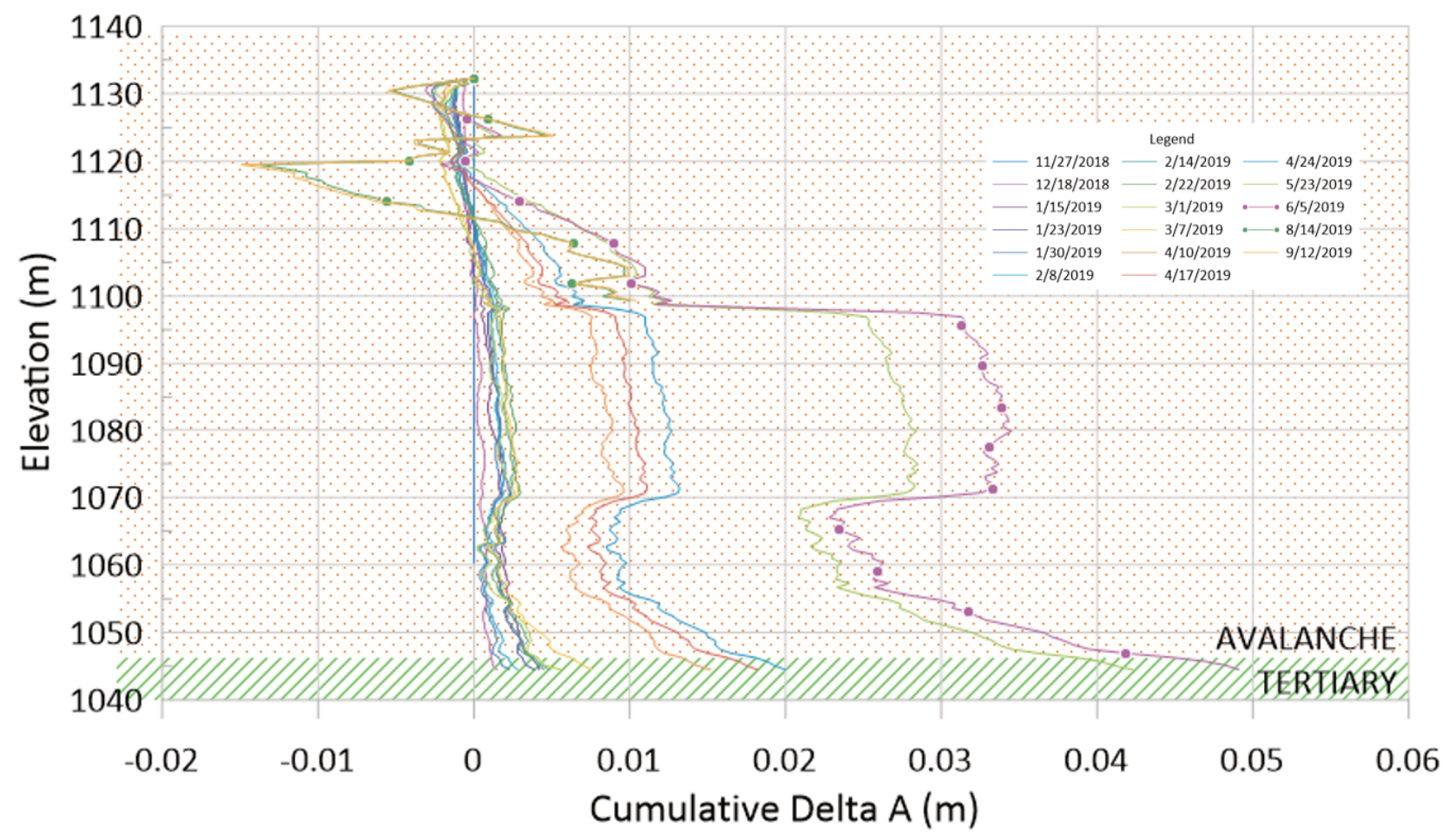

Figure 8 DP307 cumulative A axis (top-down)

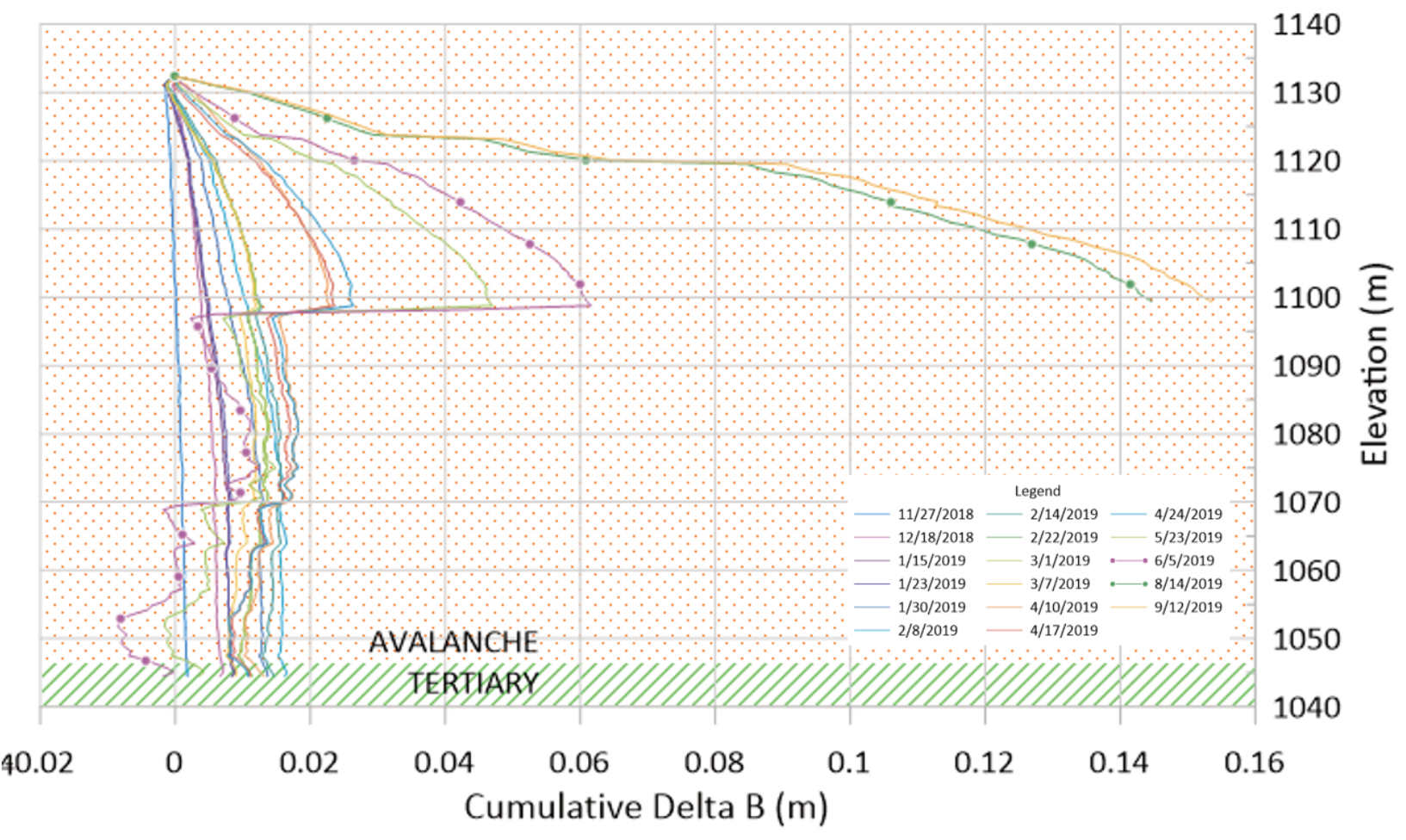

Figure 9 DP307 cumulative B axis (top-down)

\subsection{Enhanced network smart markers}

Due to technical problems early in the trial, ENSM data was not fully captured. Unfortunately, this was the period before the inclinometer and VWP cables were sheared. As such, the data for the trial is post-shearing when the technical issues had been rectified. The period selected for the data comparison was April to July 2019 over which the data was of higher quality. 
Timestamped raw data was used to calculate marker unit tilts at each point in time. Changes in tilt were used to estimate marker displacement. Lateral marker deformation was calculated by extrapolating tilt over the length of the marker $(\sim 30 \mathrm{~cm})$ to the distance between markers.

\section{$5 \quad$ Analysis}

\subsection{Deformation data comparison}

Due to the shearing of the inclinometer casing, the comparison between ENSMs and inclinometer data concentrates on the upper section of the holes over which the data overlap. The ENSM data was calibrated against the inclinometer data from the date that was closest to the date when the ENSMs data were captured. This created the ENSMs baseline absolute displacement for the hole.

ENSM data was then processed to calculate the relative displacement compared to the previous datasets. The relative displacement was then added to the calibrated absolute displacement to calculate the absolute displacement. Figures 10 to 15 compare the absolute displacement of the inclinometer (depth versus displacement, in metres) and the ENSMs for both instrumentation holes and at dates that are relatively close.

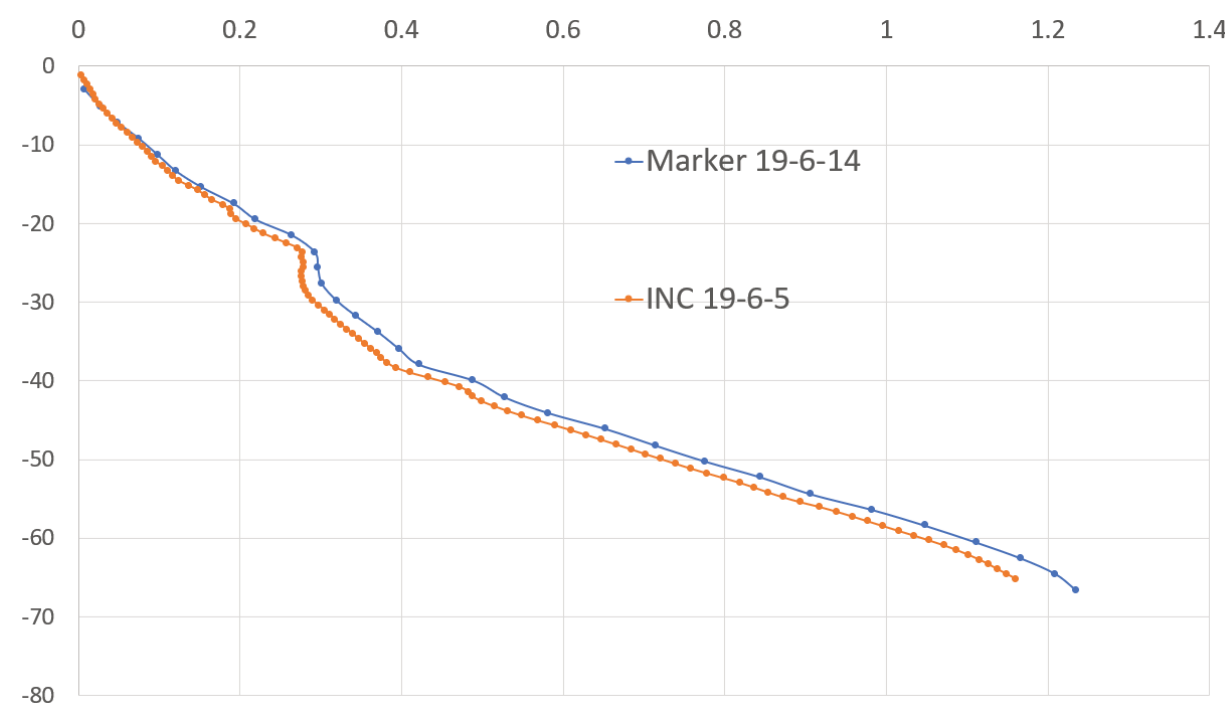

Figure 10 DP306 - Inclinometer and enhanced network smart markers cumulative displacement comparison

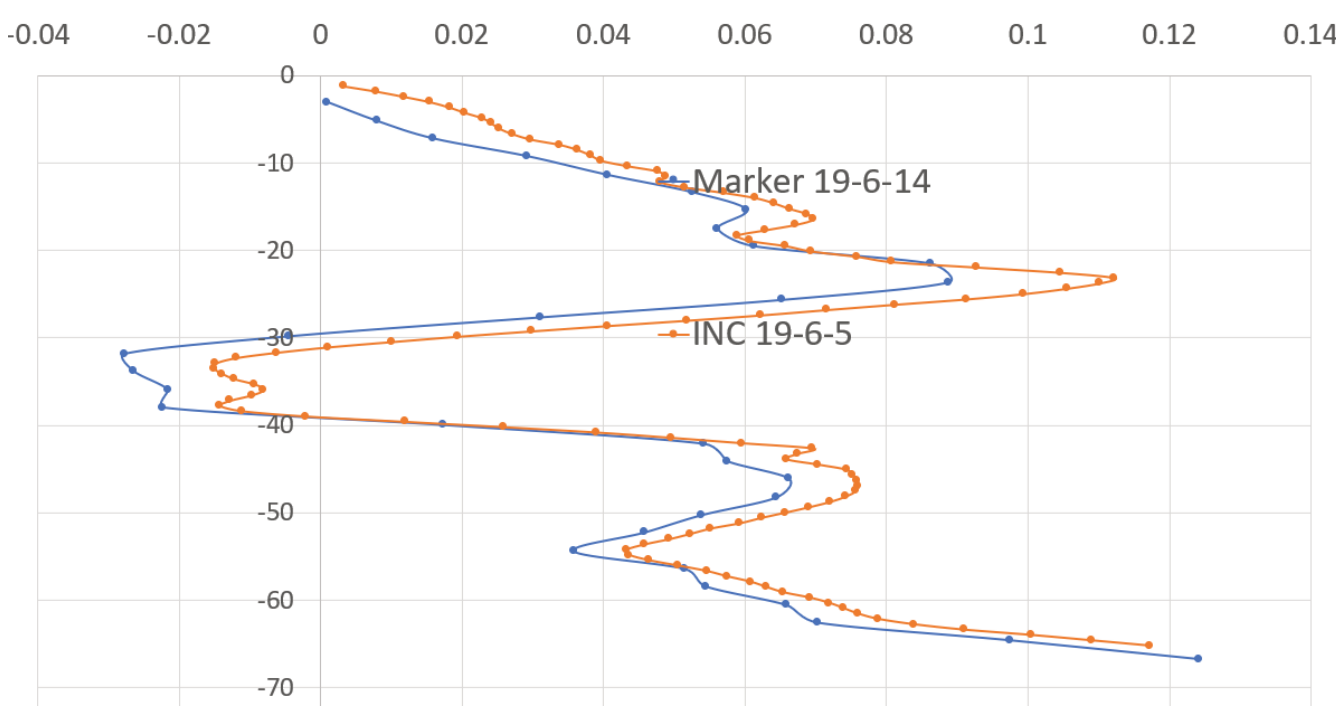

Figure 11 DP306 - Inclinometer and enhanced network smart markers cumulative east-west displacement comparison 


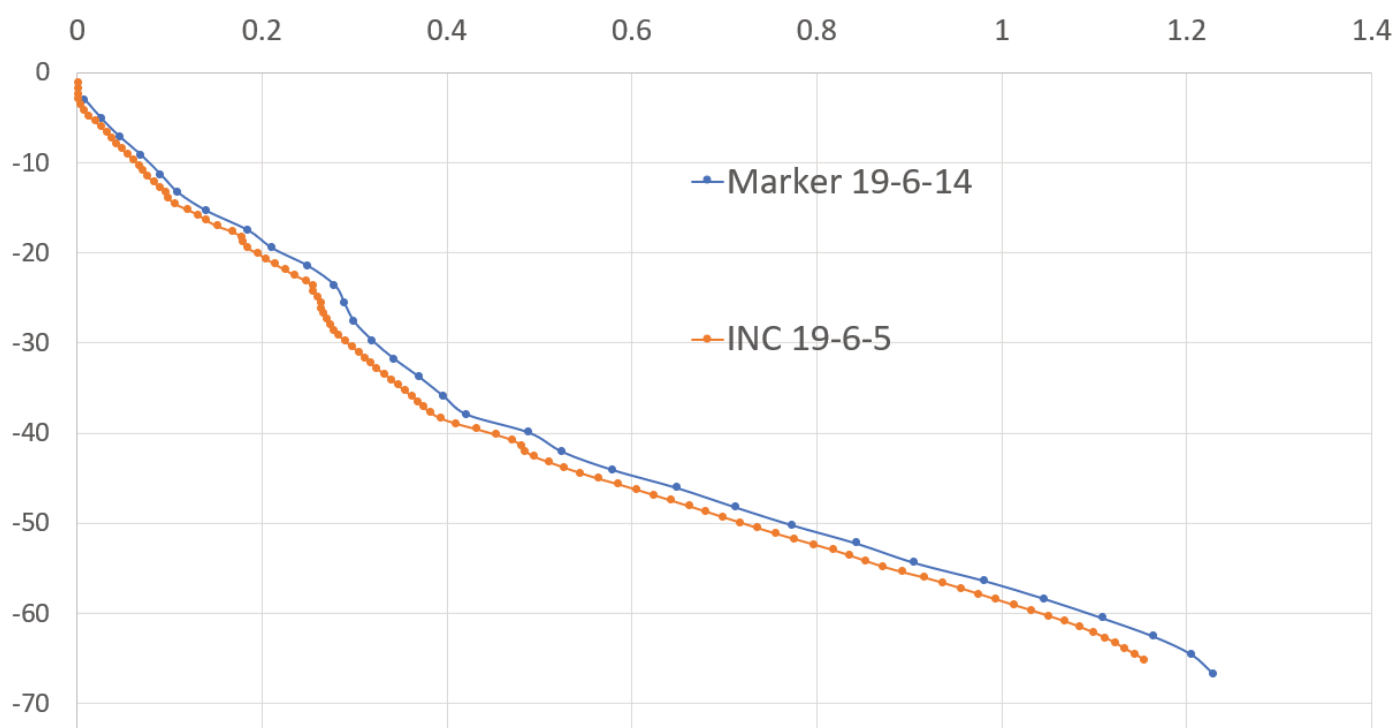

Figure 12 DP306 - Inclinometer and enhanced network smart markers cumulative north-south displacement comparison

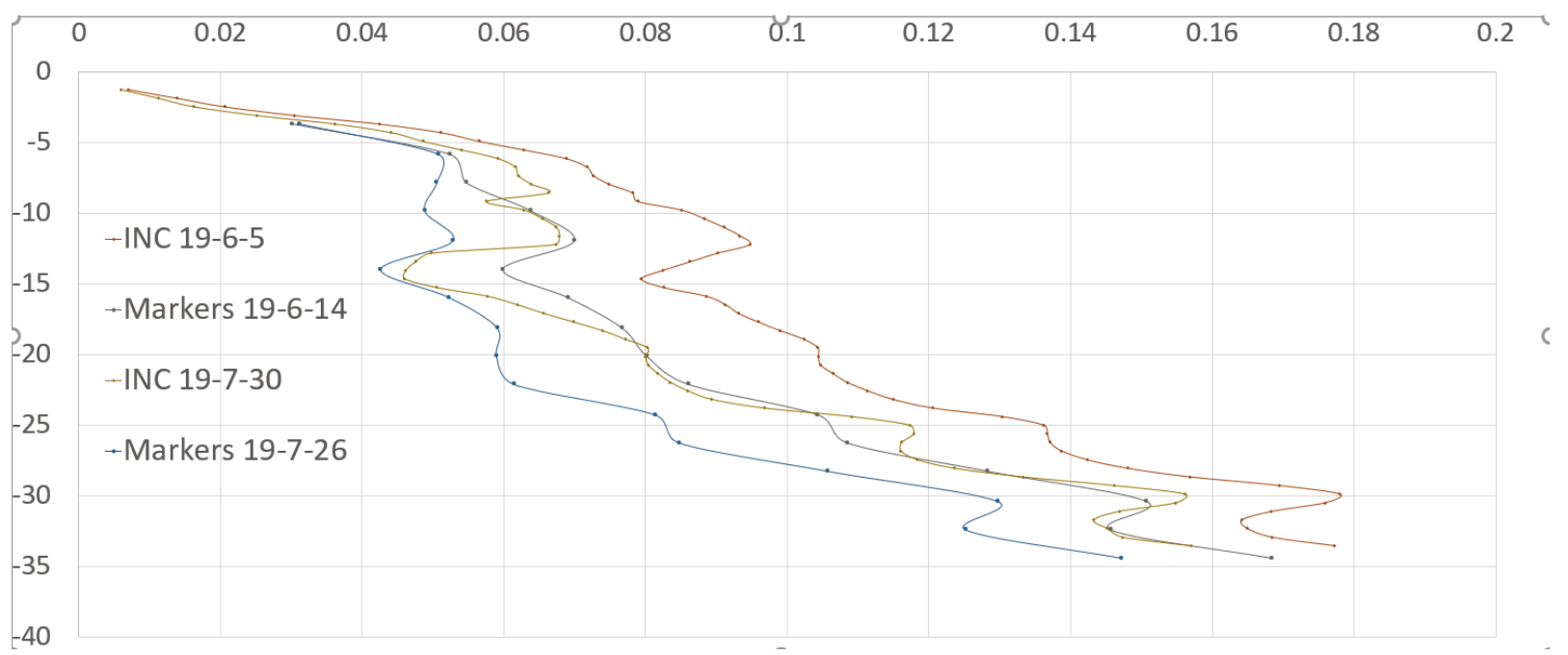

Figure 13 DP307 - Inclinometer and enhanced network smart markers cumulative absolute displacement comparison

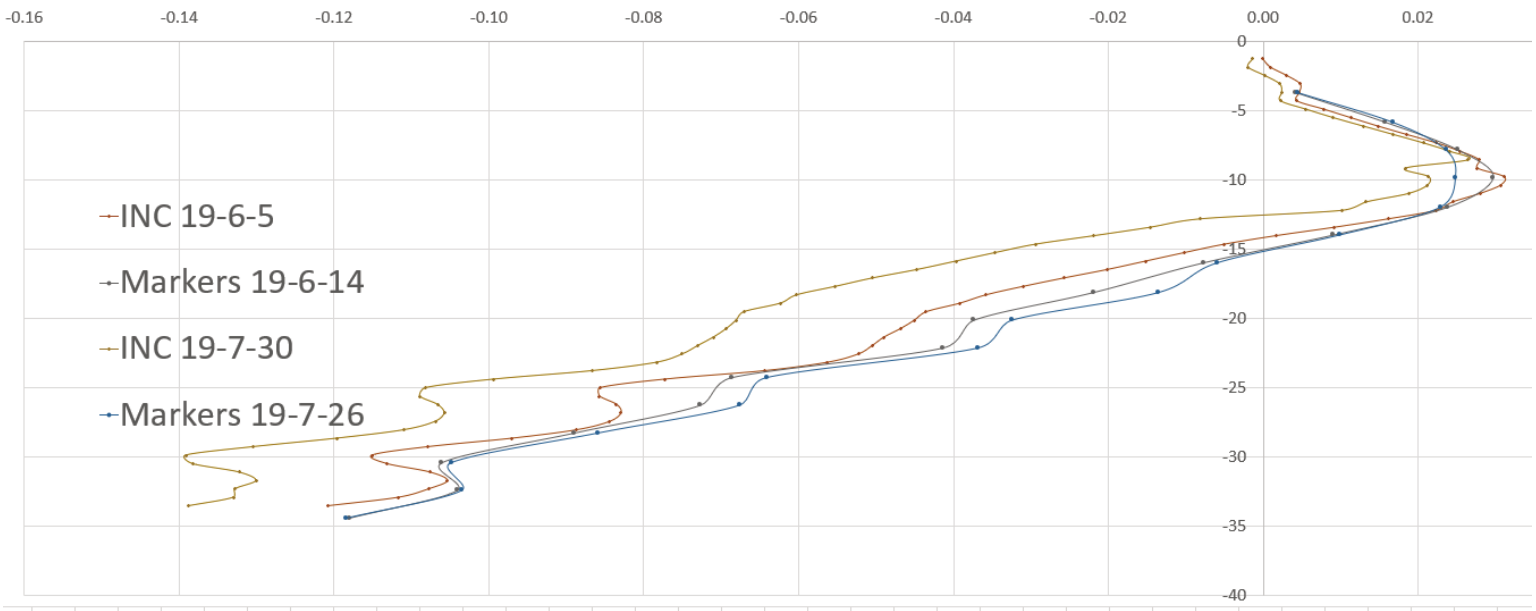

Figure 14 DP307 - Inclinometer and enhanced network smart markers cumulative east-west displacement comparison 


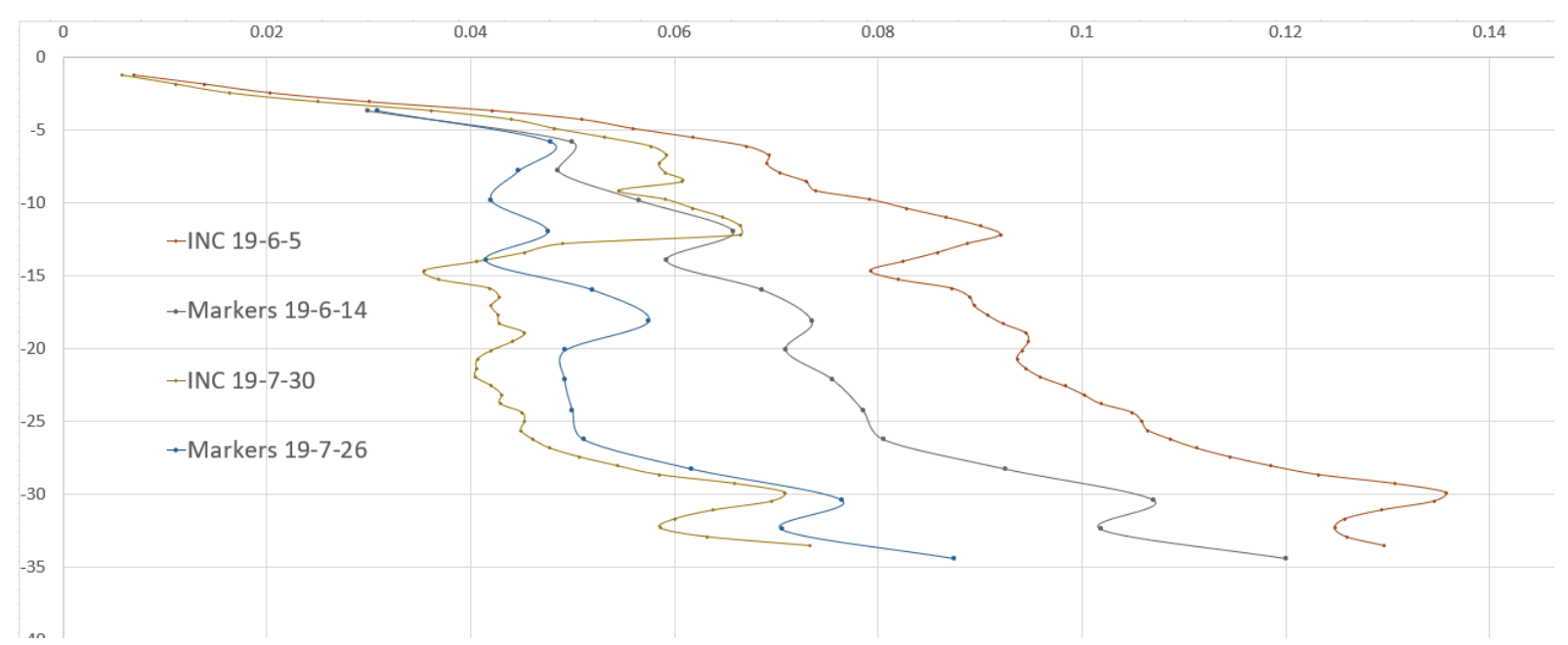

Figure 15 DP307 - Inclinometer and enhanced network smart markers cumulative north-south displacement comparison

The azimuth and tilt values of the ENSM plots show inconsistencies over time and inconsistency with the known direction of wall movement (northwest into the pit). However, the inclinometer data also has similar issues, with larger cumulative deformation values along the $B$ axis than the $A$ axis. Despite the installation including centralisers and an anchor, it is likely that the inclinometer pipe spiraled during installation, which could explain this anomaly.

The comparison of the ENSM and inclinometer data after a period of up to three and a half months has highlighted the following:

- ENSMs correlate well for the general trend of the displacement and for displacement features that span over more than $2 \mathrm{~m}$ of the downhole axis.

- Localised displacement of the scale smaller than $2 \mathrm{~m}$ in the downhole axis may not be detected by ENSMs. This is due to the lower density of datapoints along the axis of the hole. In the case that these small-scale displacement features need to be monitored, ENSMs could be installed closer together.

- ENSMs and the inclinometer data differ somewhat in the calculated magnitude of movement. The maximum difference between the inclinometer and ENSM data sets for DP307 was around $20 \mathrm{~mm}$ over a length of $35 \mathrm{~m}$ and around $40 \mathrm{~mm}$ over the length of $65 \mathrm{~m}$ for DP306. This difference is deemed as not significant and acceptable for this application.

- The calculated displacement divided by north-south, east-west also appear to correlate well, and the above comments apply.

After a relatively short period, the performance of the ENSMs appears to be within the sensitivity and the accuracy required for the targeted application. Further long-term trials will provide further insights into the system performance.

\subsection{Data collection below shear plane}

As illustrated in Figures 16 and 17, the inclinometer data ENSM data continued recording below the various shear surfaces. Increased deformation values were recorded in the ENSM data, which appear to generally correspond with the available surficial slope data. The current deformation surface from all data sets indicates shearing along the base of the avalanche (tertiary contact) in the pit, accompanied by shearing within the avalanche and tertiary units. 


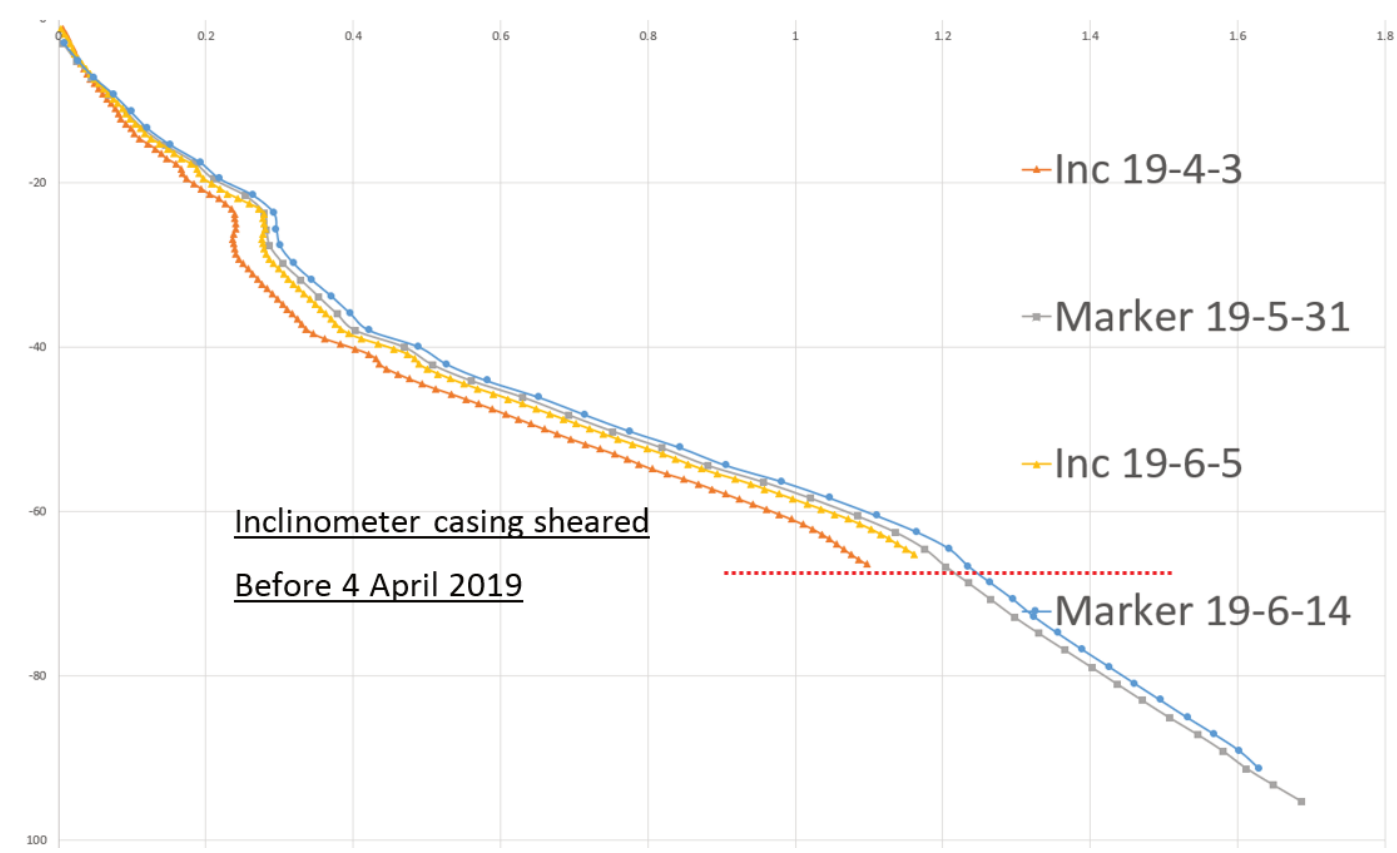

Figure 16 DP306 - Inclinometer and enhanced network smart markers cumulative absolute displacement comparison

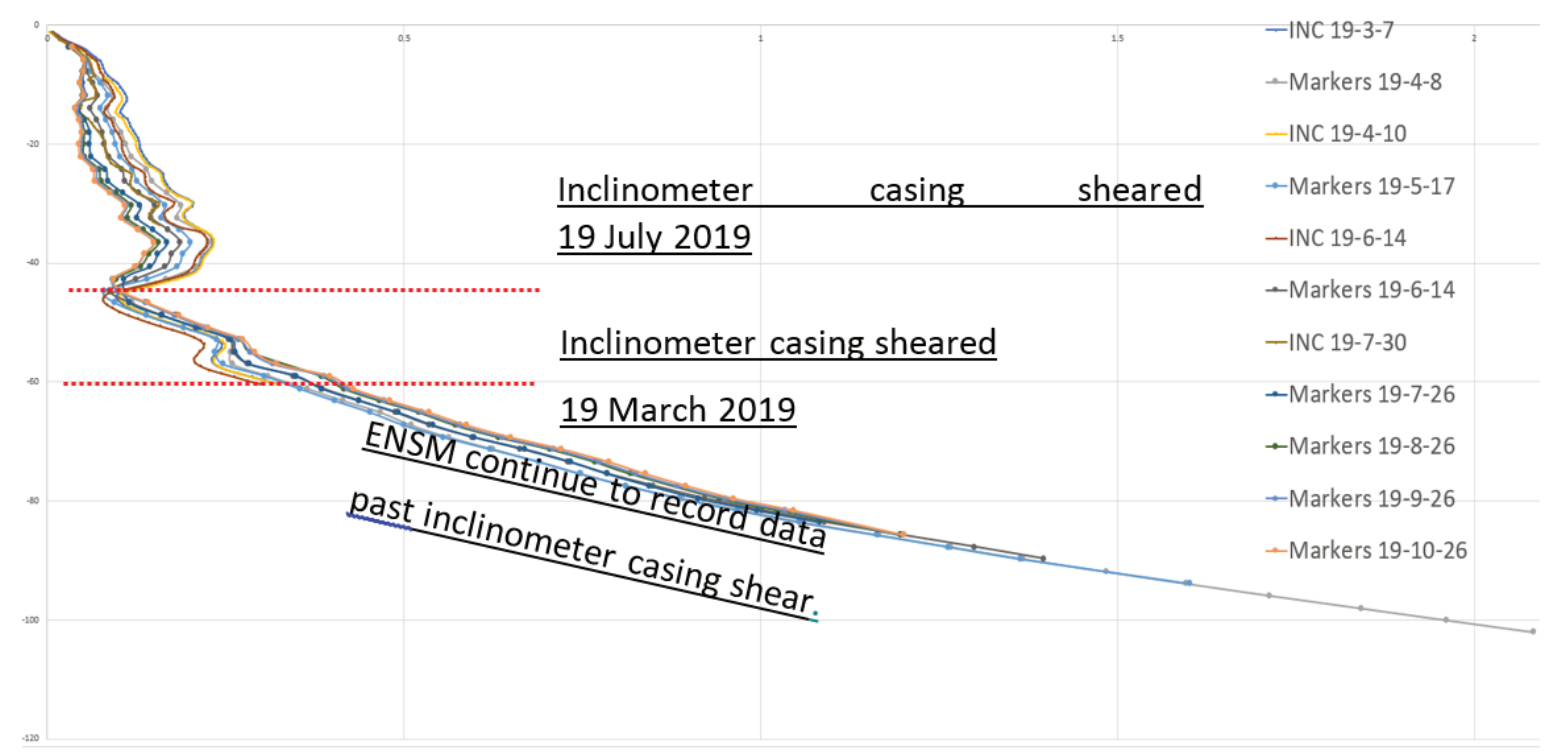

Figure 17 DP307 - Inclinometer and enhanced network smart markers cumulative absolute displacement comparison

\section{$6 \quad$ Piezometric data collected}

Piezometric data was collected from both standard VWPs and ENSM pressure transducers. Both types of sensors collect a pressure reading, which is then converted into a corresponding water elevation calculated from the sensor position and pressure at the piezometer tip. Data was not available from RST piezometers located below the shear surface after shearing of the cables occurred at the avalanche-tertiary contact. ENSM piezometers were able to collect data past this date and continue to provide pressure data.

\subsection{Piezometric data comparison}

Figure 18 illustrates the calculated water elevations for both datasets. In general, positive correlations exist between the datasets. It is important to note that the area in which the installations were located was subject 
to a number of mining activities which altered the pore pressures recorded in the datasets (observed as transient depressurisation and recovery events/curves). The relative head differences between the VWP and marker data are considered to be a difference in correction factors between the two systems, as well as relative differences in installation height. The difference between the two systems show generally consistent differences in head of about a few metres and the correlation is considered reasonable.

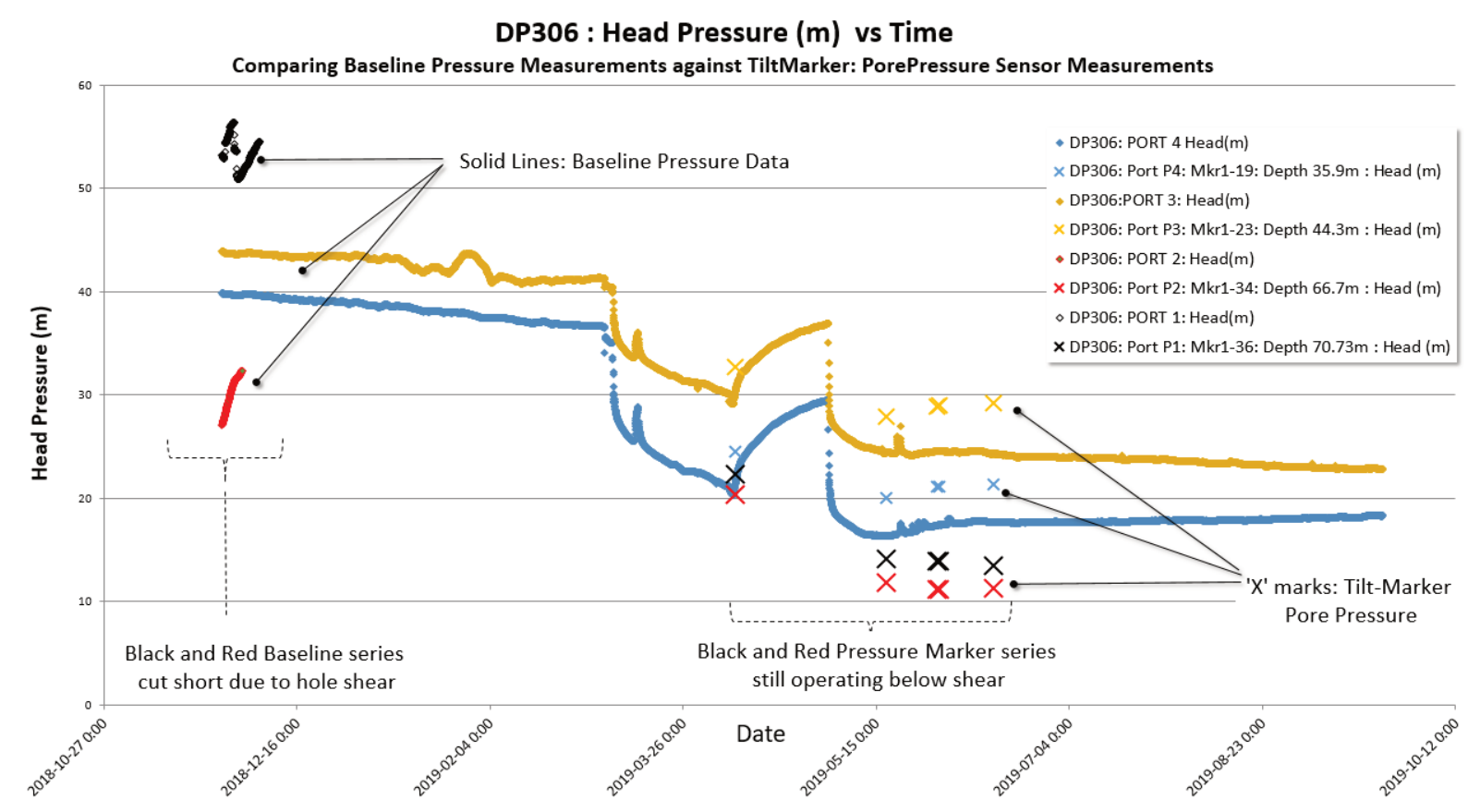

Figure 18 Piezometric plot comparison

\section{Conclusion}

ENSMs appear to show merit in open pit zones where standard installations of downhole instrumentation would otherwise be difficult to maintain operability in zones of deformation. The trial showed that relatively minor amounts of shearing render inclinometer and piezometers inoperative, whereas ENSMs continue to work. The datasets of the VWPs and ENSM pressure sensors are comparable.

Deformation data for the ENSM system will require further study to provide a more consistent dataset of downhole deformation. Lessons learned in the THVC initial trial installations have been used in subsequent test installations on other sites. Modifications have been made to installation methods for better initial calibration of the instruments. Additionally, changes in data capture and management, and data processing (used to produce figures above), are now being used to provide simpler and more visual assessment of movement data in 3D for use in stability monitoring.

\section{Acknowledgement}

The authors acknowledge Teck Resources Ltd for permission to publish this paper, for supporting the initial trial of this new instrumentation system, and for ongoing support to allow for additional testing to help advance this new system of monitoring high deformation slopes.

\section{References}

Mikkelsen, PE \& Green, GE 2003, 'Piezometers in fully grouted boreholes', in F Myrvoll (ed.), Proceedings of the $6^{\text {th }}$ International Symposium on Field Measurements in Geomechanics, CRC Press, Boca Raton, pp. 545-553, https://www.zeminas.com.tr/docs/ZET_2.pdf

Rose, N 2015, Summary of 2015 rock mass and overburden strength parameters, report memorandum prepared for Teck Resources Ltd. RST Instruments Ltd 2012, Inclinalysis digital inclinometer analysis software, version 2.47, computer software, RST Instruments, Richmond, https://www.rstinstruments.com/product/lateral-ground-displacement/inclinalysis-inclinometer-analysis 